\title{
Experimental Organism Benign Basalioma
}

National Cancer Institute

\section{Source}

National Cancer Institute. Experimental Organism Benign Basalioma. NCI Thesaurus.

Code C103391.

A benign epithelial neoplasm arising from primary epithelial germ cells of the piliary complex. 